\title{
Análisis de un modelo de desarrollo ecoturístico en Quintana Roo, México DOI: $10.22403 /$ UQROOMX/TYP01/02
}

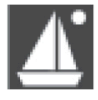

Arturo Carballo-Sandoval ${ }^{*}$

RESUMEN

El desarrollo del ecoturismo ha cobrado fuerza en los últimos 20 años. En algunos países y en ciertas regiones del mundo ha prosperado de manera importante, como es el caso de Costa Rica, Canadá y Australia. Sin embargo, estos países no están a salvo de críticas sobre las consecuencias de su propio desarrollo ecoturístico. Desde el ángulo preservacionista-conservacionista es muy difícil encontrar un desarrollo ecoturístico ideal. Lamentablemente, ha crecido con mayor fuerza un desarrollo turístico masivo o convencional con concepción antropocéntrica que, desde luego, ha sido blanco de severas críticas por las negativas consecuencias ambientales y socio culturales que ha causado. Este trabajo analiza las posibilidades de coexistencia de un modelo de desarrollo ecoturístico dentro de un modelo de desarrollo turístico masivo. Se plantea por tanto, que la actividad ecoturística puede implementarse y reforzarse a partir de un desarrollo de infraestructura turística convencional. Analiza igualmente algunas modalidades que se derivan del ecoturismo, las cuales, pueden tener particular éxito en el caso de Quintana Roo, como pueden ser el turismo rural comunitario, el turismo de aventura y el turismo arqueológico.

Palabras $\mid$ Quintana Roo, desarrollo turístico, modelo de desarrollo,

CLAVE turismo, ecoturismo

"Instituto Tecnológico de Cancún / acarballo@itcancun.edu.mx 
Análisis de un modelo de desarrollo ecoturístico en

Quintana Roo, México

\section{Antecedentes}

La actividad turística representa un sector económico dinámico para el país y particularmente para el estado de Quintana Roo. Las estadísticas sobre el ingreso de turistas internacionales y la consecuente derrama económica, así lo demuestran. Se traduce por tanto en un significativo detonador de desarrollo para la región del Caribe mexicano por la generación de empleos, inversión, divisas, infraestructura de servicios y, en general, por el desarrollo económico que este sector de servicios produce. Sin embargo, se convierte en un imperativo observar, analizar y, fundamentalmente, cuidar esta actividad económica para que no genere consecuencias negativas en el ambiente propio en el que se desenvuelve. Es preciso proteger la vasta riqueza cultural y los recursos naturales sin los cuales la actividad turística no prosperaría.

México cuenta con una extraordinaria cantidad de atractivos naturales y socioculturales que lo convierten en uno de los principales destinos turísticos a nivel mundial. A todo lo largo y ancho del país se encuentran vestigios arqueológicos, producto de esa gran riqueza histórica de la nación, que pertenecieron y pertenecen a distintos grupos étnicos que enriquecen la oferta de atractivos culturales. Ciudades coloniales y pueblos autóctonos representan también activos turísticos de particular belleza. México igualmente ofrece una amplia variedad de platillos típicos regionales que lo convierte en una de las cocinas más representativas, exquisitas y ricas en el ámbito culinario. Montañas, ríos, lagos y lagunas son una gran muestra y ejemplo de las potencialidades que la actividad turística puede aprovechar. Destinos de playa como Cancún, Cozumel, Playa del Carmen, Isla Mujeres, Bahías de Huatulco, Acapulco, Ixtapa-Zihuatanejo, Puerto Vallarta, Mazatlán, Los Cabos y Loreto Nopoló, entre otros, han convertido al país en uno de los principales destinos turísticos en el mundo. México, de acuerdo con estadísticas de la Organización Mundial del Turismo (OMT), ocupa el octavo lugar en llegadas internacionales y el duodécimo en ingresos por concepto de turismo internacional, como se observa en las tablas 1 y 2 , respectivamente. 
Carballo-Sandoval

TABLA I. LOS I5 PRIMEROS DESTINOS tURísticos EN EL MUNDO (1999-2000).

\begin{tabular}{lllcc}
\cline { 3 - 4 } & & \multicolumn{2}{c}{$\begin{array}{c}\text { Llegadas de Turistas } \\
\text { Internacionales (Millones) }\end{array}$} & $\begin{array}{c}\text { Porcentaje de } \\
\text { Variación }\end{array}$ \\
\hline Rango & País & 1999 & 2000 & $2000 / 1999$ \\
\hline I & Francia & 73.0 & 75.5 & 3.4 \\
2 & Estados Unidos & 48.5 & 50.9 & 4.9 \\
3 & España & 46.8 & 48.2 & 3.0 \\
4 & Italia & 36.5 & 41.2 & 12.8 \\
5 & China & 27.0 & 31.2 & 15.5 \\
6 & Reino Unido & 25.4 & 25.2 & -0.8 \\
7 & Rusia & 18.5 & 21.2 & 14.5 \\
8 & México & 19.0 & 20.6 & 8.4 \\
9 & Canadá & 19.5 & 20.4 & 4.9 \\
10 & Alemania & 17.1 & 19.0 & 10.9 \\
11 & Austria & 17.5 & 18.0 & 2.9 \\
12 & Polonia & 18.0 & 17.4 & -3.1 \\
13 & Hungría & 14.4 & 15.6 & 8.1 \\
14 & Hong Kong & & & \\
& (China) & 11.3 & 13.1 & 15.3 \\
15 & Grecia & 12.2 & 12.5 & 2.8
\end{tabular}

Fuente: OMT, 200I.

\section{Situación actual del turismo en el estado de Quintana Roo}

El estado de Quintana Roo es el multidestino más importante de México y de la región del Caribe. Lo anterior se desprende de los indicadores turísticos de fuentes como la Secretaría Estatal de Turismo, las asociaciones de hoteles de Cancún y Cozumel, el Fideicomiso de Promoción Turística de la Riviera Maya y el Instituto Nacional de Migración. Estos indicadores muestran que se recibieron 3913242 turistas en el año 200I, los cuales generaron una derrama económica de \$3 I34 millones de dólares americanos (Sedetur, 200 I). Para satisfacer esta demanda, se cuenta con una infraestructura hotelera de 622 hoteles y 5I 263 cuartos, que registraron una ocupación promedio anual de $69 \%$. Es importante destacar que en lo particular Cancún y la Riviera 
Análisis de un modelo de

desarrollo ecoturístico en

Quintana Roo, México

TABLA 2. LOS I5 PAISES DEL MUNDO EN INGRESOS POR TURISMO INTERNACIONAL 1999-2000.

34

\begin{tabular}{clccc} 
& & $\begin{array}{c}\text { Ingresos por Turismo Internacional } \\
\text { (Miles de Millones } \$ \text { EEUU) }\end{array}$ & $\begin{array}{c}\text { Porcentaje de } \\
\text { variación }\end{array}$ \\
\hline Rango & \multicolumn{1}{c}{ País } & 1999 & 2000 & $2000 / 1999$ \\
\hline I & Estados Unidos & 79.4 & 85.2 & 13.7 \\
2 & España & 32.4 & 31.0 & -4.3 \\
3 & Francia & 31.5 & 29.9 & -5.1 \\
4 & Italia & 28.4 & 27.4 & -3.2 \\
5 & Reino Unido & 20.2 & 19.5 & -3.4 \\
6 & Alemania & 16.7 & 17.8 & 6.5 \\
7 & China & 14.1 & 16.2 & 15.1 \\
8 & Austria & 12.5 & 11.4 & -8.7 \\
9 & Canadá & 10.2 & 10.8 & 5.9 \\
10 & Grecia & 8.8 & 9.2 & 5.0 \\
11 & Australia & 8.0 & 8.4 & 5.3 \\
12 & México & 7.2 & 8.3 & 14.8 \\
13 & Hong Kong (China) & 7.2 & 7.9 & 9.4 \\
14 & Turquía & 5.2 & 7.9 & 46.8 \\
I5 & Rusia & 7.5 & - & -
\end{tabular}

Fuente: Омт, 200I.

Maya registraron una ocupación promedio estatal del 78.3\% (Sedetur, 200I). En el segmento de turismo de cruceros, Quintana Roo es el líder nacional; de acuerdo con la Asociación Portuaria Integral de Quintana Roo (APIQROo), en puertos de Cozumel, Playa del Carmen y Costa Maya se registraron I 294 arribos de cruceros con una afluencia general de I 918445 turistas (APIQROO, 200I). Estas estadísticas evidencian la importancia económica del sector turístico para Quintana Roo, que, según informes de la Secretaría Estatal de Turismo (Sedetur), cada cuarto de hotel en el estado genera aproximadamente siete empleos directos, sumando aún más los indirectos.

Es importante mencionar que Cancún y Cozumel son los puntos más próximos a Europa y la costa este de los Estados Unidos. Esta situación 
geográfica desde luego, representa una sustancial ventaja comparativa con respecto a Centro y Sudamérica. Según informes de la Sedetur, en Quintana Roo, el aeropuerto de Cancún realiza el mayor número de operaciones, reportando durante 200 I, el $93.5 \%$ de las mismas.

Las tablas 3 y 4 muestran las llegadas de turismo internacional a Cancún en el periodo 1988-200I y la derrama económica a los principales destinos turísticos del Caribe mexicano en el periodo 1996-2000. Esta información demuestra que el estado de Quintana Roo y particularmente Cancún y la Riviera Maya, tienen un importante futuro en la actividad turística, eje del desarrollo económico del estado (Carballo-Sandoval, 200I).

TABLA 3. Llegadas de TURISMo INTERNACIONAL A CANCÚN (1988-200I)

\begin{tabular}{lc}
\hline Año & Número de Llegadas \\
\hline 1988 & 657504 \\
1989 & 857066 \\
1990 & $1 \quad 180504$ \\
1991 & 1432351 \\
1992 & 1558373 \\
1993 & 1492401 \\
1994 & 1448282 \\
1995 & 1671985 \\
1996 & 1835992 \\
1997 & 2069281 \\
1998 & 2664199 \\
1999 & 2818326 \\
2000 & 3044682 \\
2001 & 3913242
\end{tabular}

Fuente: Secretaría de Turismo (SECTUR), 1999 y Secretaría Estatal de Turismo (SEDETUR), 2000. 
Análisis de un modelo de desarrollo ecoturístico en

Quintana Roo, México

TABLA 4. DerRama eCONÓMICA EN lOS PRINCIPALES DESTINOS TURÍSTICOS DEL Caribe mexicano 1996-2000 (Millones de \$EEUU).

36

\begin{tabular}{lrrrrr}
\hline Destino & 1996 & \multicolumn{1}{c}{1997} & \multicolumn{1}{c}{1998} & \multicolumn{1}{c}{1999} & \multicolumn{1}{c}{2000} \\
\hline Cancún & 1704.0 & 2051.8 & 2045.5 & 2358.8 & 2896.1 \\
Riviera Maya & 290.0 & 293.5 & 407.0 & 520.4 & 774.5 \\
Cozumel & 281.2 & 327.1 & 398.3 & 320.1 & 349.8 \\
Isla Mujeres & 25.1 & 25.6 & 83.0 & 39.3 & 40.5 \\
Chetumal & 8.5 & 9.8 & 10.0 & 12.0 & 16.0
\end{tabular}

Fuente: Secretaría de Turismo (SECTUR), 1999 y Secretaría Estatal de Turismo (SEDETUR), 2000.

\section{Ecoturismo, turismo sustentable y desarrollo sustentable}

La Unión Mundial para la Naturaleza (UICN) define al ECOTURISMO como aquella modalidad turística ambientalmente responsable, consistente en la visita a áreas naturales con el fin de disfrutar sus atractivos (paisaje, flora y fauna silvestres), así como sus manifestaciones culturales del presente o del pasado, a través de un proceso que promueva su conservación (Ceballos-Lascuráin, 1998). Propicia la participación activa de las poblaciones locales en su desarrollo de manera que le permitan obtener beneficios sociales y económicos. Tiene bajo impacto ambiental y cultural.

El ecoturismo:

- Debe ser participativo: involucrar a la comunidad en todo el proceso de su desarrollo, desde el conocimiento de recursos y atractivos naturales y culturales, hasta el monitoreo de la operación turística.

- Debe ser progresivo: hay que manejar el producto turístico en forma no explosiva o acelerada, y en la medida en que la sociedad local va conociendo la experiencia turística.

- Debe ser planificado: no puede ser espontáneo pues se manejan recursos delicados y requiere la participación de diferentes actores.

- Debe ser integral: abordar la totalidad del territorio y los temas involucrados con el desarrollo turístico. 
Sólo mediante el diseño lineamientos estrictos y su cumplimiento, se podrá garantizar que el ecoturismo no se convierta en un agente dañino para el patrimonio natural o cultural de un país o región. Es por ello que el ecoturismo es una modalidad del turismo sustentable, que a su vez se inserta dentro del marco general de desarrollo sustentable. Este último ha sido definido como un patrón de transformaciones estructurales de índole socioeconómica que optimiza los beneficios sociales y económicos del presente, sin poner en riesgo el potencial para obtener beneficios similares en el futuro (Cater, 1994). Por tanto, el turismo sustentable es todo aquel turismo (ya sea basado en recursos naturales o no) que contribuye al propio desarrollo sustentable.

México, por su ubicación geográfica tan próxima a los Estados Unidos de América, debería ocupar la más alta posición como destino ecoturístico extranjero preferido de los norteamericanos. Sin embargo, parece que no es así, debido en gran medida a que se ha hecho hasta ahora muy poco para promover la imagen ecoturística de México a nivel internacional (CeballosLascuráin, 1998).

Modelo de desarrollo ecoturístico dentro de un destino turístico masivo

Mucho se ha escrito acerca de ecoturismo y turismo masivo. Se ha llegado a afirmar que estos tipos de 'turismo' difícilmente puedan tener afinidades concretas.Weaver (200I) menciona que un modelo de desarrollo ecoturístico pudiera existir dentro de un destino turístico masivo. Es importante señalar que estos tipos de turismo no se llevarían a efecto en el mismo punto geográfico (por ejemplo, Cancún) pero si en la región adyacente de un destino turístico masivo. En tal sentido, muchas comunidades aledañas pueden verse beneficiadas significativamente. Recordemos que el ecoturismo depende en gran medida y como punto de apoyo de la infraestructura del turismo masivo: grandes hoteles, aeropuertos y agencias de viajes.

Este artículo propone que se desarrolle en el estado de Quintana Roo un tipo de ecoturismo comunitario, turismo rural o turismo arqueológico, obedeciendo a las características de la oferta de servicios que se pueden implementar y en respuesta a una demanda que bien se puede aprovechar en este destino turístico del Caribe mexicano. 
Análisis de un modelo de

desarrollo ecoturístico en

Quintana Roo, México

\section{Ecoturismo comunitario, turismo rural y turismo arqueológico: alternativas de desarrollo con enfoque sustentable para el estado de Quintana Roo}

El turismo sustentable en sus diversas modalidades, como el ecoturismo comunitario, el turismo rural y el turismo arqueológico, representa una alternativa para las regiones sur y centro del estado de Quintana Roo, debido a que se cuenta con numerosos vestigios mayas, recursos naturales atractivos para los visitantes, tradiciones culturales de gran interés, además de ser la puerta de entrada al Mundo Maya del propio estado de Quintana Roo. La integración de centros de acopio y agronegocios como alternativas en estas dos regiones, presentan un incentivo para reactivar la producción del medio rural y en consecuencia poder desarrollar, asimismo, un tipo de turismo rural que mucho beneficiará a las comunidades anfitrionas participantes.

El estado de Quintana Roo cuenta con una variedad de áreas naturales protegidas que forman parte de la Comisión Nacional de Áreas Naturales Protegidas (CONANP) en el país, que bien pueden representar las bases para desarrollar la modalidad del ecoturismo sustentable, buscando igualmente el beneficio de las comunidades cercanas a estas áreas protegidas. Es importante mencionar que la sustentabilidad de cualquier desarrollo turístico o ecoturístico implica la participación y el desarrollo equilibrado de las variables socioculturales, económicas y principalmente las medioambientales. El éxito, por tanto, de todo proyecto turístico sustentable dependerá del desarrollo armónico de estas tres dimensiones (Cater, 1994).

La Reserva de la Biosfera de Sian Ka'an, ubicada en la parte central del estado y con una extensión de $5230 \mathrm{~km}^{2}$ representa un destino que bien puede, cumpliendo algunas regulaciones y normas ambientalesconservacionales, convertirse en un destino ecoturístico clave para el desarrollo de esta parte del estado. Las normas ambientales-conservacionales están relacionadas con la densidad del uso del suelo, capacidad de carga del lugar y la estricta protección de flora y fauna silvestre, entre otras. De igual forma, existen otras áreas naturales protegidas en el estado como son los parques marinos nacionales de Cancún, Isla Mujeres y Cozumel, la reserva de la Biosfera de Isla Contoy y Holbox, Arrecifes del Banco Chinchorro, La Poza y Xcalak al sur de la entidad, entre los más destacados (véase figura I). 
Sitios, todos estos, donde las actividades turísticas son susceptibles de llevarse a cabo, redundando igualmente, en beneficios económicos, socioculturales e incluso, conservacionales para los habitantes de estas zonas.

Quintana Roo es un estado privilegiado turísticamente porque también cuenta con importantes vestigios mayas localizados a todo lo largo de la geografía de la entidad. Sitios arqueológicos como Cobá, Tulum, Akumal, Kohunlich, Xel-Há y San Gervasio, entre otros, representan importantes atractivos turísticos para una afluencia de turistas deseosos de conocer la gran riqueza maya.

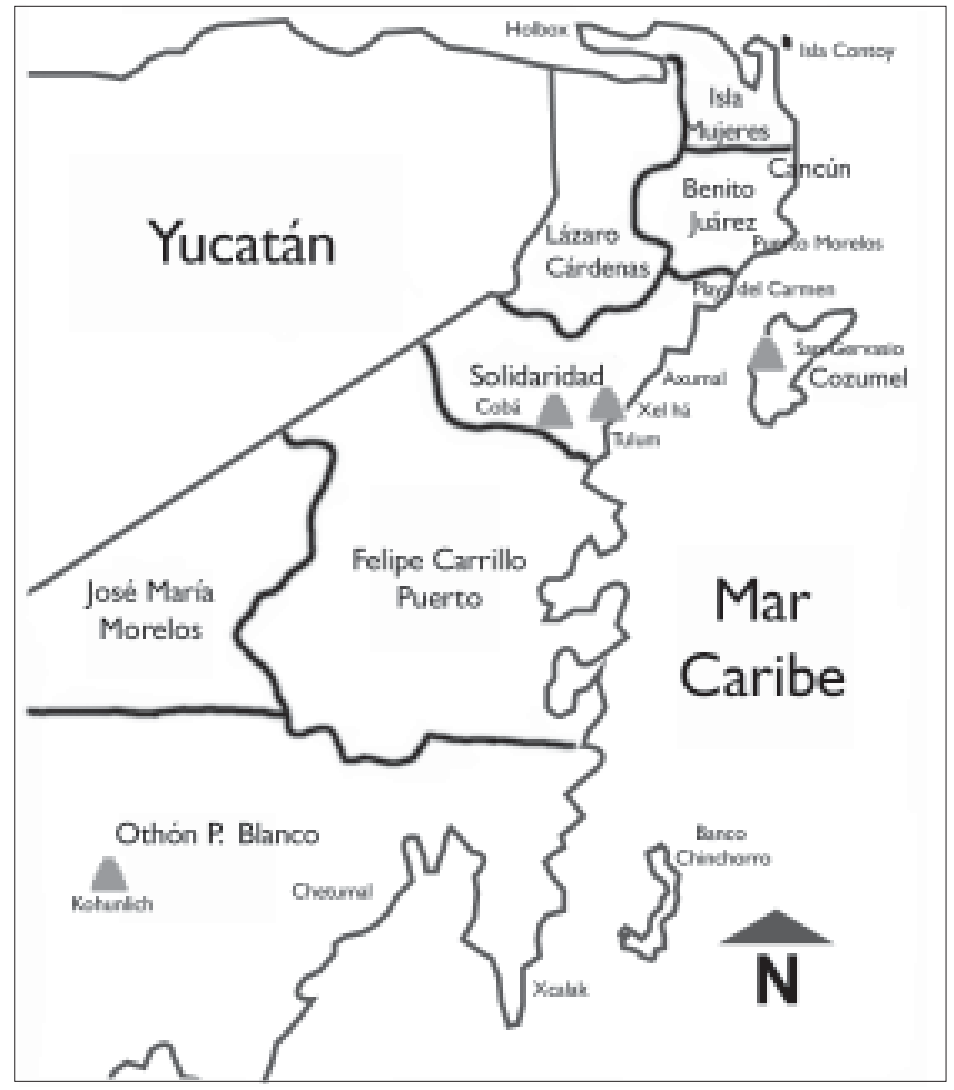

Figura I. Mapa del estado de Quintana Roo. 
Análisis de un modelo de

desarrollo ecoturístico en

Quintana Roo, México

De acuerdo con estudios realizados por la Secretaria de Turismo (Sectur), los vestigios históricos mayas son visitados fundamentalmente por un segmento de demanda turística muy especializado. Son turistas responsables que preferentemente buscan la conservación del lugar desde el punto de vista social y cultural, así como el entorno físico-ambiental. De igual manera poseen un alto poder adquisitivo que se manifiesta en la demanda económica que pueden generar. Gran parte de estos visitantes son personas con un nivel elevado de estudios y con edades que fluctúan entre los 30 y 50 años, características que los convierten en turistas con principios de ética y responsables. Este segmento de mercado es el que debe interesar al Caribe mexicano para garantizar su equilibrio.

En la región sur del estado, el proyecto de desarrollo turístico de la Costa Maya, es igualmente una realidad. El arribo de los primeros cruceros en el año 2000 es una muestra significativa de los beneficios económicos que traerá consigo este nuevo desarrollo. De acuerdo con informes del gobierno del estado de Quintana Roo, se avanza hacia la conclusión de la ampliación y modernización de la carretera Chetumal-Majahual, que permitirá integrar a las comunidades del área de influencia con este centro turístico, beneficiándose además a las localidades de Bacalar, Chetumal y Felipe Carrillo Puerto en la generación de la oferta de bienes y servicios, aminorando la desigualdad regional en la entidad.

Como se señaló antes, los beneficios que la actividad turística puede acarrear al estado son múltiples, dentro de éstos se contempla los socioculturales, económicos y conservacionales, tales como:

- Generar empleos directos e indirectos

- Atraer inversiones, fundamentalmente nacionales e internacionales

- Generar divisas

- Propiciar desarrollo local, regional y nacional

- Distribuir armónicamente la renta nacional (turismo doméstico)

- Generar e impulsar el efecto multiplicador

- Conservar y reforzar los valores socioculturales de las comunidades participantes

- Propiciar un efecto demostrativo positivo

- Valorar la participación de la mujer en la actividad turística

- Fortalecer la identidad de las comunidades anfitrionas 
- Establecer planes de ordenamiento del uso del suelo

- Proteger los recursos naturales, base esencial de todo desarrollo turístico

- Promover políticas de protección y conservación de los atractivos turísticos naturales

Estrategias sustentables de desarrollo ecoturístico a implementarse:

- Establecer un modelo de desarrollo ecoturístico en el que participen conjunta y armónicamente empresas locales y foráneas, líderes y autoridades comunitarias, autoridades de gobierno municipal y estatal, operadores de viaje y comunidad en general.

- Buscar siempre el liderazgo en la actividad ecoturística principalmente en la aplicación, cumplimiento y observación de los códigos y decretos en materia ambiental conservacional.

- Lograr tanto el posicionamiento del producto/servicio ecoturístico comunitario como la competitividad en el mercado, garantizando con ello el fortalecimiento de la economía local.

- Lograr que las comunidades adquieran poder y evitar el paternalismo.

- Trabajar coordinadamente con dependencias de gobierno (estatales y federales), asociaciones y grupos ambientalistas, organismos no gubernamentales (ONG), instituciones educativas y centros de investigación, a efecto de monitorear y evaluar los impactos (positivos y negativos) derivados de la actividad ecoturística.

Adicional al cumplimiento de las estrategias anteriores es necesario que se cubran las siguientes condiciones o requisitos para desarrollar ecoturismo comunitario en la zona:

Elementos para su planeación y desarrollo:

- Definir objetivos y metas en el corto, mediano y largo plazo

- Propiciar un clima propositivo, pro e interactivo entre los actores participantes

- Involucrar a los habitantes de la comunidad en todas las etapas de la planeación

- Inventariar estricta y cuidadosamente los recursos naturales (atractivos turísticos) de la zona y establecer prioridades de protección y conservación 
Análisis de un modelo de

desarrollo ecoturístico en

Quintana Roo, México

- Conocer y cumplir el ordenamiento del territorio y los criterios de construcción y urbanización (densidad del uso de la tierra)

- Respetar absolutamente el régimen de áreas protegidas

- Establecer códigos de conducta turística

- Elaborar estudios precisos para analizar las capacidades de carga de la zona

- Definir los productos y servicios ecoturísticos (oferta) en congruencia con la satisfacción de las necesidades del ecoturista (demanda)

- Monitorear y evaluar constantemente los impactos derivados de la actividad ecoturística

\section{Promoción y mercadotecnia del ecoturismo}

Toda actividad de mercadotecnia en el campo del ecoturismo se compone de diversas etapas, mismas que se debe observar y cumplir a efecto de conseguir los logros esperados. Las etapas son:

Obtención de inventarios de atractivos o actividades existentes.

¿Qué tenemos en nuestra área protegida que pueda interesar a los ecoturistas? Clasificar los atractivos en focales, complementarios y de apoyo será una gran ventaja. Los atractivos focales son los activos básicos que un área ofrece a los visitantes, son los recursos o atributos más atrayentes que posee el área, de carácter natural (paisaje, flora o fauna silvestre) y/o cultural (patrimonio arqueológico, tradiciones arqueológicas, artesanías), sin perturbar. Los atractivos de apoyo son elementos artificiales que complementan la actividad turística.

En el caso del estado de Quintana Roo:

- Costa marina de extraordinaria belleza

Playas de blanca arena

Aguas limpias, transparentes y cálidas

Oleaje tranquilo y pacífico

Caletas naturales

- Segunda barrera arrecifal más grande del mundo

Abundancia de peces coralinos 
Existencia de fosas y cavernas

Extensa flora coralina

- Abundante riqueza florística y faunística de la región

- Un clima natural bondadoso gran parte del año

- La hospitalidad del pueblo quintanarroense

- Cercanía con el mercado norteamericano

- Gran civilización maya

Vasto patrimonio histórico y cultural

Rica arquitectura maya

Cuna del mestizaje

- Tradiciones, folclor, gastronomía, arte, escultura, aún presentes.

Identificación de los segmentos apropiados del mercado

Identificar los segmentos potencialmente más importantes del mercado ecoturístico, con base en características geográficas y de comportamiento de la oferta y la demanda.

Para lograr una mejor segmentación del mercado podemos plantearnos las siguientes preguntas:

a) ¿Qué tipo de visitantes podrían estar interesados en los atractivos que ofrecemos?

b) ¿A quiénes podríamos atraer para visitarnos?

c) ¿Quiénes queremos que nos visiten?

d) ¿Dónde viven? ¿Qué idioma hablan? ¿Qué revistas leen?

e) ¿Qué programas de televisión prefieren? ¿Cuáles son sus principales intereses?

f) ¿Qué nivel educativo y cultural tienen? ¿En qué rango de edades se encuentran? ¿La proporción de hombres y mujeres es la misma o varía? ¿Cuál es su nivel de ingresos y cuánto están dispuestos a gastar en sus vacaciones?

g) ¿Cuáles son sus habituales actividades turísticas? ¿Qué otros destinos ecoturísticos desean conocer?

h) ¿Qué les gusta hacer? ¿Qué tan fácilmente pueden viajar a nuestra área? ¿Cómo deciden sobre sus destinos ecoturísticos? ¿Qué hacen en camino a su destino ecoturístico? ¿Qué actividades les ofrecemos? 
Análisis de un modelo de

desarrollo ecoturístico en

Quintana Roo, México

Lo más importante es decidir qué grupos meta serán los más adecuados para los objetivos de nuestros destinos ecoturísticos y las áreas protegidas y comunidades locales asociadas a ellos. Atraer un tipo de mercado u otro determinará el tipo y el perfil de la industria turística que el área en cuestión desea desarrollar, así como las estrategias para comunicarse con los turistas potenciales.

Algunos expertos en turismo han comentado la conveniencia de segmentar el mercado de los viajes, afirmando que existen muchos cruzamientos entre categorías. Sin embargo, la segmentación, aunque se admite que es un tanto artificial, puede ayudar a clarificar la manera de pensar de los principales grupos potenciales del mercado y cómo empaquetar y vender los destinos ecoturísticos. Finalmente, la existencia de turistas interesados en visitar destinos naturales es lo que impulsará a que existan operadores ecoturísticos, quienes a la vez podrán ayudar a convencer a las autoridades oficiales competentes para que establezcan más áreas protegidas (o consoliden las ya existentes) como parte de una estrategia integral de turismo y conservación del medio ambiente.

Tenemos cuatro tipos básicos de turistas de la naturaleza o ecoturistas:

- De corazón. Investigadores científicos o viajeros con una alta motivación científica que participan en tours diseñados con orientación marcadamente científica, educativa o ambientalista.

- Dedicados. Aquellas personas que realizan viajes específicamente para visitar áreas naturales (sobre todo las protegidas) y que desean adquirir conocimientos sobre la historia natural y cultural de los sitios que visitan.

- Convencionales.Aquellos turistas que van al Amazonas, a los parques nacionales africanos y otros destinos naturales con la idea principal de realizar un viaje "exótico" o "poco usual".

- Casuales. Turistas que visitan áreas de interés natural simplemente porque éstas forman parte del itinerario de un viaje de intereses de carácter general.

Otro aspecto de gran importancia es lo referente a los precios al consumidor. ¿Cuáles son los niveles de ingreso de los viajeros que nos interesa 
atraer? ¿Cuánto está dispuesto a pagar un turista por una experiencia en particular? ¿Cuál es el costo de proveer esa experiencia? Si cierta área protegida puede ser combinada con otros destinos turísticos, ¿Cuál es el costo adicional por visitar esa área protegida?

\section{Evaluación del grado de atractivo comparativo del producto}

Una vez que se ha determinado lo que un área o región y su comunidad pueden ofrecer a los turistas y qué tipo de turistas es factible que vengan, habrá que enfrentar los atractivos y actividades con los segmentos específicos del mercado. Hay que realizar una estimación sobre si la capacidad de carga del medio ambiente y las instalaciones turísticas son suficientes para satisfacer la demanda esperada y si dicha demanda basta para proveer ingresos adecuados, asimismo, verificar si son adecuados los servicios de apoyo, la infraestructura requerida, los senderos de la naturaleza, miradores, observatorios, áreas de aparcamiento y muelles, centros interpretativos, instalaciones para acampar, servicios sanitarios, tratamiento de desechos, alojamiento y alimentación, primeros auxilios, acceso para minusválidos, combustible requerido para vehículos y embarcaciones.

\section{Estrategia y actividades promocionales}

La publicidad debe dirigirse a un grupo específico de ecoturistas potenciales a través de anuncios pagados en periódicos, TV, radio, revistas, cartelones, así como a través de ferias turísticas, folletos y envíos personalizados por correo.

Al compartir gastos de promoción y otros entre los diferentes sectores involucrados, los costos para cada sector disminuirán considerablemente y la promoción podrá ser de un carácter más integrado y útil para el ecoturista. Una campaña promocional de carácter integrado deberá estar basada en folletos ilustrados, de preferencia en material reciclado, y en spots televisivos y radiofónicos.

Las secretarías vinculadas con turismo, medio ambiente y áreas protegidas deberán colaborar en campañas a nivel regional, nacional e internacional, a las cuales deberán sumarse el sector empresarial y las ONG.

Cada medio es efectivo de manera distinta y es apropiado para diferentes niveles presupuestales. Pueden diseñarse campañas para promover un destino ecoturístico desconocido, o para cambiar la manera en que un área o región 
Análisis de un modelo de

desarrollo ecoturístico en

Quintana Roo, México

es percibida o para recordar al público de sus beneficios y atractivos. Quien se anuncia paga para tener el control sobre el contenido y forma del mensaje, incluyendo cuándo, cómo debe verse y oírse.

Se requiere de una estrategia de comunicación y de ventas para estimular a los clientes reales y potenciales a tener conocimiento del producto turístico y que lo compren. La importancia de las revistas y otras publicaciones periódicas no podrá menospreciarse.

El ecoturismo en las modalidades que aquí se analizan (ecoturismo comunitario, turismo rural y turismo arqueológico) deberá hacer uso intensivo y extensivo de las nuevas tecnologías de comunicación electrónica, tanto para diseminar información, realizar promoción y comercialización, como para facilitar las reservaciones. El internet y el correo electrónico se han convertido en los mecanismos preferidos de intercambio y obtención de información entre muchos ecoturistas, sobretodo en países más industrializados.

\section{Conclusión}

México, en general, y particularmente el estado de Quintana Roo han incursionado positivamente en el mercado turístico mundial, asimismo han fortalecido los segmentos de demanda del turismo doméstico. Las estadísticas claramente indican los resultados económicos derivados del turismo internacional. Quintana Roo, por tanto, presenta una vocación directa para el desarrollo del turismo. Es importante, sin embargo, que implemente y fortalezca modalidades sustentables del turismo como: ecoturismo comunitario, turismo rural y turismo arqueológico. Asimismo, es esencial que diversifique otras actividades económicas, de tal suerte que no dependa sustancialmente de la actividad turística. En la medida que el estado fortalezca otras actividades como la agricultura, la pesca, la ganadería y los servicios, paralelas al desarrollo turístico, sin duda alguna habrá mayores oportunidades para el fortalecimiento de la economía en la entidad. De antemano sabemos que el turismo genera empleos directos e indirectos, así como inversiones, divisas y desarrollo local y regional. La actividad turística mejora la calidad de vida de los habitantes del destino turístico, es importante por ello, consolidar y participar activamente en su planeación y desarrollo. 
FUENTES CONSULTADAS

APIQRO (200I). Cancún, Quintana Roo: Administración Portuaria Integral del Estado de Quintana Roo.

AHMCC (2002). Estadísticas. Quintana Roo: Asociación de Hoteles y Moteles de Cancún y Cozumel.

Carballo-Sandoval, A. (200I). Community Involvement in Sustainable Ecotourism:The case of the Mexican Caribbean. Tesis doctoral. Reino Unido: Universidad de Reading, Departamento de Geografía.

Cater, E. (I 994). “Ecotourism: dimensions of sustainability”, en J. Bornemeier y P. Durst (eds). Ecotourism for Forest Conservation and Community Development. RECOFT, Report No. I 5. Chiang Mai.Tailandia. 1997.

Cater, E. (1994). Ecotourism:A Sustainable Option? Londres:The Royal Geographical Society \& Wiley Sons.

Ceballos-Lascuráin, H. (1998). Ecoturismo: naturaleza y desarrollo sostenible. México: Diana, $185 \mathrm{p}$.

OMT (200I). Panorama mundial y actualidad del turismo. Madrid: OMT, 28 p.

---- (200I) Tendencias de los mercados turísticos. Madrid, España: OMT 94 p. Sedetur (200I). Compendio de Estadísticas. Cancún, Quintana Roo, México: Secretaría Estatal de Turismo.

Weaver, D. (200I). "Ecotourism in the Context of Other Tourism Types" en, Weaver, D. (ed.). The Encyclopedia of Ecotourism. Reino Unido: CABI Publishing. 


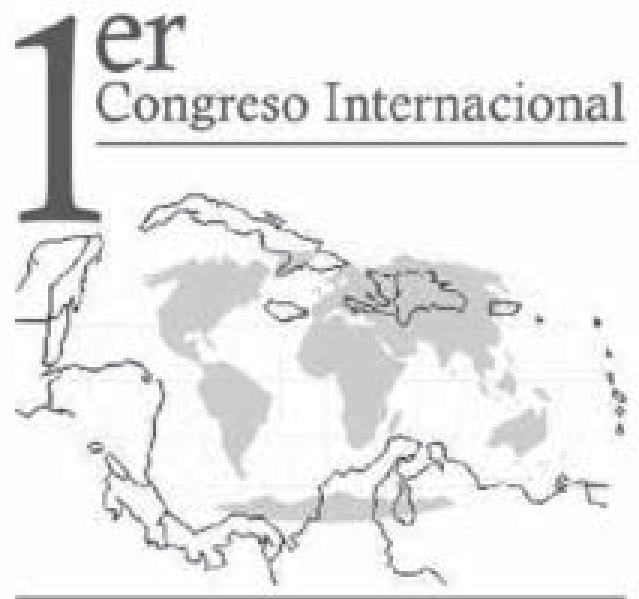

Administración y Negocios en el Caribe Realidad Competitiva: Perspectivas al 2015

\section{7 al 29 de octubre de 2005 Universidad de Quintana Roo Unidad Académica Cozumel}

Mesa 1. Economia del Caribe

Situación del Caribe en la economia internacional Economia y empresa Politicas economicas

Impacto del turismo en la economia reglonal

2Hiloque exonómico del Caribe?

Economia y negocios ilicito:

Mesa 3. Desarrollo sustentable y negocios

Negocies sustentables en el Caribe Desarrollo sustentable y empresas

Administración bajo la optica de la sustentabilidad

Politicas ambientales $y$ negocios

Mesa 5. Politicas publicas

Politicas pubblicas y negocios

Marco legal de los negocios

Instrumentos derivadios de las politicas publicas

Organismos multilaterales y politicas públicas

Politicas püblicas y negocios alicitos
Mesa 2. Mercadotecnia y negocios turisticos

Mercadotecnia estrategica y negocios turisticos Mercadotecnia de productos y servicios turistices Impacto de la mercadotecnia en los

negocios turisticos

Mercadotecnia sustentable en negocios turisticos Comportamiento del consumidor de productos y servicios turisticos

Mesa 4. Educacion y cultura

Discriminación entre latinos

Educacion y negocios

Cultura y negocios

Programas educativos de negocios zcon calidad?

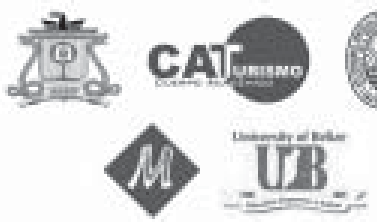

\section{Informes}

Mtro. Alejandro Alvarado Herrera

perspectivas20015

www.cozumel.uqroo.mx 